\title{
South African Journal

\section{Investigating ICTs for information dissemination to alumni of the newly merged University of Johannesburg}

\author{
Z. Barnard \\ Centre for Information and Knowledge Management \\ University of Johannesburg \\ Johannesburg, South Africa \\ zb@adfin.rau.ac.za

\section{Rensleigh} \\ Centre for Information and Knowledge Management \\ University of Johannesburg \\ Johannesburg, South Africa \\ cr@rau.ac.za
}

\section{Contents}

1. Introduction

\subsection{Research problem}

2. Alumni of the University of Johannesburg

3. New media for disseminating information to alumni

4. Possible effects of the digital divide on information dissemination to alumni of the UJ

5. Empirical research

5.1 Research methodology

5.2 Research findings

6. Conclusion

7. References

Key words: Information dissemination, higher education, ICT, alumni

\begin{abstract}
1 Introduction
This article is based on a Masters dissertation that investigated the extent to which Information and Communication Technologies (ICTs) could enable the Alumni Office of the University of Johannesburg, as a newly merged institution, to disseminate information effectively to its alumni. The merger in January 2005 of the Rand Afrikaans University (RAU) and the Technikon Witwatersrand (TWR) to form the University of Johannesburg (UJ) is bound to have a significant impact on the present and future alumni of both institutions. Seen from an affinity point of view, three different groups will come into existence, namely the alumni of the RAU, the alumni of the TWR and the alumni of the UJ. Owing to different historic, academic and socio-economic backgrounds, the divergent demographic profiles of these target groups will, in all probability, prove challenging to UJ Alumni Office staff members' endeavour to establish and maintain vibrant alumni relations for the newly forged UJ.
\end{abstract}

\begin{abstract}
Experience has shown that the essence of these relationship-building activities is the dissemination of information through a variety of media and in accordance with an integrated information-communication strategy. The interactive nature and the implementation of such a specific strategy will, therefore, be a key to the success of the alumni relations of the newly formed UJ. Fortunately, information technology creates a platform from which this could be effected in a cost-effective and timely manner, even though information technology cannot and should not automatically be deemed the main channel for information dissemination, especially in the light of the so-called 'digital divide' prevalent in South Africa, with all its complications and influencing factors.
\end{abstract}

The Alumni Office of the newly forged UJ would have to take cognizance of all these influencing factors when devising an informationcommunication strategy for effective information dissemination. It would, for this reason, be a most worthwhile exercise to establish the extent to which the Internet and other information technologies could be utilized in this pursuit.

\subsection{Research problem}

The research problem for this study is formulated as follows:

To what extent can ICTs enable the Alumni Office of the newly merged UJ to disseminate information effectively to its alumni?

\section{Alumni of the University of Johannesburg}

For the UJ, which will be much more than the sum of the parts of what was once the RAU (incorporating the Soweto and East Rand campuses 
of Vista) and the TWR, the support of its existing and prospective alumni is fundamental to the realization of its vision, mission and corporate objectives. The inevitable initial vulnerability (in terms of market share, brand value, etc.) of the UJ could be greatly reduced if the alumni, although a part of different affinity groups within the institution, could be won over to buy into the new values and objectives that have been decided upon for the UJ. This would reinforce the position of the UJ in the higher-education environment, when its new brand, corporate identity and reputation need to be established. At the core of relations between the UJ and its alumni lies an interactive communication network by means of which relevant information needs to be disseminated effectively in order to establish lasting relations with this stakeholder group.

The value that alumni could add (financially, strategically and/or socially) to the credibility and longevity of their Alma Mater (Stone 2001) should be made applicable to the mutual benefit of both the alumni and the UJ. The input they could have in terms of institutional fundraising activities, institutional council representation, networking and community development could significantly contribute to the strategic positioning of the UJ as a market leader in the South African higher-education sector. The alumni's potential for becoming the primary candidates for lifelong learning at the new UJ should also be recognized and encouraged, to the benefit of all parties concerned.

Gorman (1989) points out that 'failure to recognise the risks of mergers where cultures are significantly different, the costs of changing those cultures (in terms of people, time, dollars and even institutional reputation) can be fatal'. At the core of these relationship-building efforts stands the frequent dissemination of relevant information and interactive communication between the Alumni Office and its alumni. Every possible avenue should, therefore, be explored to realize and develop the interactive communication process. The emergence of ICTs has created opportunities to simplify the execution of these communication activities in modern-day life significantly, which further supports the objective to build a network of participating alumni for the new institution.

\section{New media for disseminating information to alumni}

To optimally exploit the convenience and cost-effectiveness that ICTs offer, the Alumni Office of the UJ needs to be informed about the available ICTs that would help to sustain the relationship-building efforts with the different alumni affinity groups. It is of critical importance for the Alumni Office of the UJ to keep abreast of the needs and resources of its alumni if an interactive alumni network were to be established with the help of ICTs. Knowledge of this would enable the Alumni Office to customize the information it is disseminating, according to the channel of dissemination and content, to establish an interactive information-sharing network.

Fitzgerald (2003:3) points out that 'communicating with the consumer-cantered, digital generation is an adjustment for many alumni organizations, and it requires far more than a Web presence. This group demands that we become much more knowledgeable and creative in our online communications.' If the Alumni Association of the UJ manages to meet the information and communication needs of its alumni, it is believed that the challenges brought about by the merger of RAU and TWR, and the amalgamation of diverse cultures, could be faced and successfully conquered to the mutual benefit of all stakeholders involved.

\section{Possible effects of the digital divide on information dissemination to alumni of the UJ}

According to Cullen (2001:1), the term 'digital divide' refers to the gap that exists between those people who have access to, as well as the skills to operate, ICTs and those people who have no access to these technologies, who may not even be aware of their existence and/or do not have the skills to utilize them. It would be of little or no use if the Alumni Office was to try and communicate with alumni by means of ICTs, and the intended receivers of the information had neither access nor the skills to operate the technologies that would allow their decoding of the message. In South Africa factors influencing the digital divide include socio-economic circumstances, gender and age, level of education, language barriers and culture, attitude and self-perception, race, geographical distribution and lack of infrastructure. Many of these factors, however, are interrelated.

As graduates should all be literate and able to speak, write and understand English as an academic language, the level of education and language barriers are not perceived as obvious influencing factors in the technological usage patterns of the alumni of a higher-education institution. Socio-economic circumstances could, however, play a significant role in ICT access, as these graduates might have had access to technology (computers, telephones, etc.) while on campus, but might not have the means to acquire these technologies after graduation. In South Africa, being a graduate does not automatically imply being employed, as the high unemployment rate makes entering the job market an extremely challenging endeavour for young, inexperienced graduates. There may also be a very real possibility, therefore, that the alumni of a South African tertiary institution such as the UJ (consisting of RAU and TWR alumni) may not have the means to access ICTs. This situation could be exacerbated if the graduate were to go back to a family life in a rural environment, with little or no infrastructure.

The attitudes and self-perceptions of graduates of a tertiary institution with regard to their utilization of technology are anticipated to be better than those of individuals who have had little or no contact with information systems. Owing to the fact that many South African university and technikon courses offer computer and information literacy as compulsory subjects in their curricula, students are trained from their first year to use computers, even if they have never had any previous experience with these systems. The result is more self-assured and competent users of technology once the students have graduated. It is expected that this confidence would greatly contribute to their willingness to utilize and embrace new technology as information and communication tools later in their lives, regardless of their gender and/or age.

The use of ICTs could be a tool to speed up and simplify the process of mobilizing the existing university resources (i.e. alumni), as the application of these technologies is likely to pay dividends in a wide variety of areas, to the benefit of all stakeholders. If, for example, distance learning were to become a core focus of the new institution, alumni in remote areas could be reached more effectively and the learning needs with regard to adult education (for lifelong learning) could be addressed more efficiently. ICTs can make distance-learning courses more accessible to these adults, as it would create an avenue through which a more interactive learning experience could be achieved. The digital divide in South Africa could, however, hinder this process, as effective distance learning would require affordable telephone and Internet access in the remote parts of the country.

\section{Empirical research}

For the empirical study, the sample population for answering the quantitative, close-ended questionnaire via telephonic surveys was selected by means of stratified sampling, from the RAU alumni and TWR alumni databases respectively. Three hundred RAU alumni and 300 TWR 
alumni were sampled out of the total target group population, of which $25 \%$ were males older than 35 years, $25 \%$ were males 35 years and younger, 25\% were females older than 35 and 25\% were females 35 years and younger.

\subsection{Research methodology}

The research approach that was followed for this project can be classified under Pasteur's quadrant of Stokes' Research Classification Quadrants (1997), namely as 'use-inspired basic research'. This type of research is devoted to solving problems in order to improve people's lives and is, therefore, deemed the ultimate research type, considered to be both inspired by the quest for fundamental understanding and consideration of use. This research project's main objective was to discover new facts, knowledge and information about the UJ alumni's ICTs usage patterns and preferences.

The rapid development, however, of ICTs is a factor that needs to be borne in mind in terms of research time and time to application. An innovative and active research model is necessary to accommodate this ever-changing and fast-evolving environment. Action research is such a research paradigm, comprising a powerful combination of research and action (as depicted in Figure 1), which proceeds parallel to each other.

Figure 1 Action research cycle (Rowley 2004)

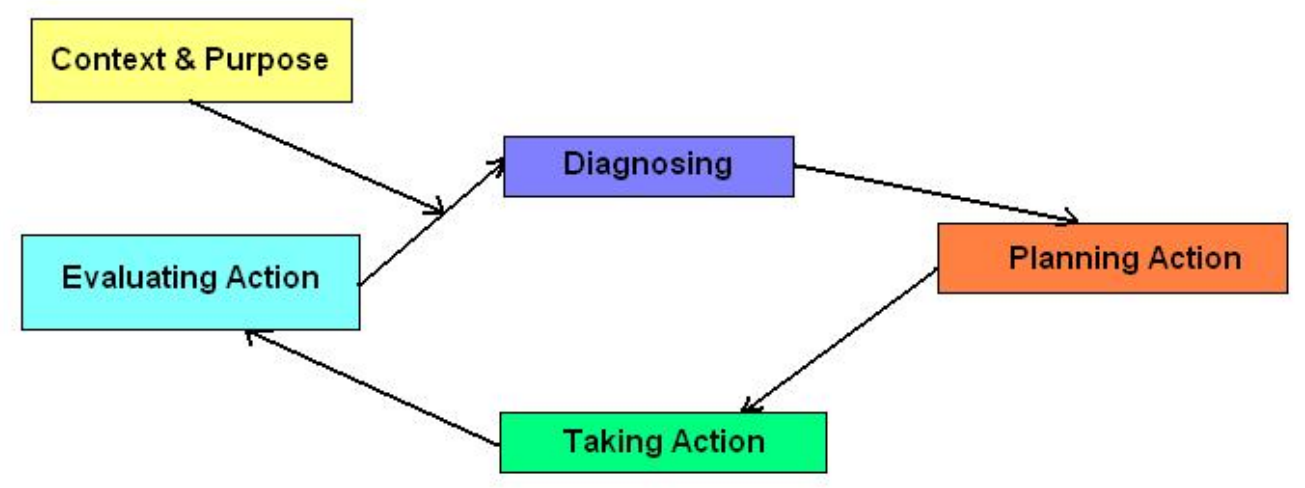

Action research can be classified under Pasteur's quadrant, as it presumes a powerful alliance between research and action, rendering the research outcomes highly organization-specific. This is a pertinent approach for the research strategy formulation and implementation in dynamic environments especially, such as that represented by the UJ. The choice of methodology for this project fell on quantitative research, as the specific variables to be measured had been identified.

A questionnaire was compiled about alumni's specific needs regarding the receiving of information (including the types of information requested, as well as the channel through which information could be received). Several close-ended questions were then formulated in accordance with the literature study that was undertaken in the theoretical context of the research. The said questionnaire consisted of three sections, namely:

Section A: Biographical information

Section B: Information and communication technology and media

Section C: Relationship building.

A telephonic survey was done to gather the empirical data. In this article, the research results from Section A and B are discussed.

For this research project (where the interdependency of the variables needed to be analysed) the null hypothesis (H0) states that there is no relationship (dependency) between the identified variables, whereas the alternative hypothesis (H1) states that a relationship (dependency) does exist between the variables. The Pearson chi-square hypothesis test for independence and Fisher's exact test were used respectively to determine the $P$ value (statistical significance). Should the $P$ value be smaller than 0,05 , the null hypothesis (H0) would be rejected in favour of the alternative hypothesis (H1), with at least a 95\% confidence. In addition, effect sizes were used due to the $P$ value's dependence on sample size.

Effect sizes determine the exact effect, instead of the difference/non-difference (d/nd) mindset. When determining the effect sizes (by means of Cramer's $V$ method and phi-coefficient), the test sample size is not an inhibiting factor, as the bigger the test sample is, the stronger the power of the test (Cohen 1998). According to Rosenthal's rule of thumb (Rosenthal et al. (author, please give the names of all the authors in this first citation) 2000), this size of the effect could be described (interpreted) as set out in Table 1.

Table 1 Rosenthal's guidelines to describe effect sizes

\begin{tabular}{|l|l|}
\hline Effect size & Interpreted effect \\
\hline $0,0-0,1$ & No effect \\
\hline $0,1-0,3$ & Small effect \\
\hline $0,3-0,5$ & Medium effect \\
\hline $0,5-1,0$ & Large effect \\
\hline
\end{tabular}

Source: Rosenthal et al. 2000

A small effect size, therefore, means that there are no (significant) dependencies between identified variables, and a large effect size shows that a significant dependency exists between identified variables (i.e. they are interrelated).

\subsection{Research findings}

\section{Section A: Biographical information}


The highest level of education of the total number of respondents was on postgraduate degree-level with 43,5\%, as can be seen in Figure 2. On degree-level the percentage came to $33,8 \%$, while $21,9 \%$ was on diploma-level. These figures show that the alumni of the UJ are part of the minority of the South African population with regards to their level of education as tertiary education is not part of the majority of South Africans' frame of reference. This could already create the expectation that the level of education would not influence the ICTs access and/or usage patterns of alumni of the UJ negatively, as literacy or level of education and technological advancement is strongly correlated with each other when it comes to the digital divide in South Africa.

Figure 2 Graphic representation of the responses to Question 4 of the survey

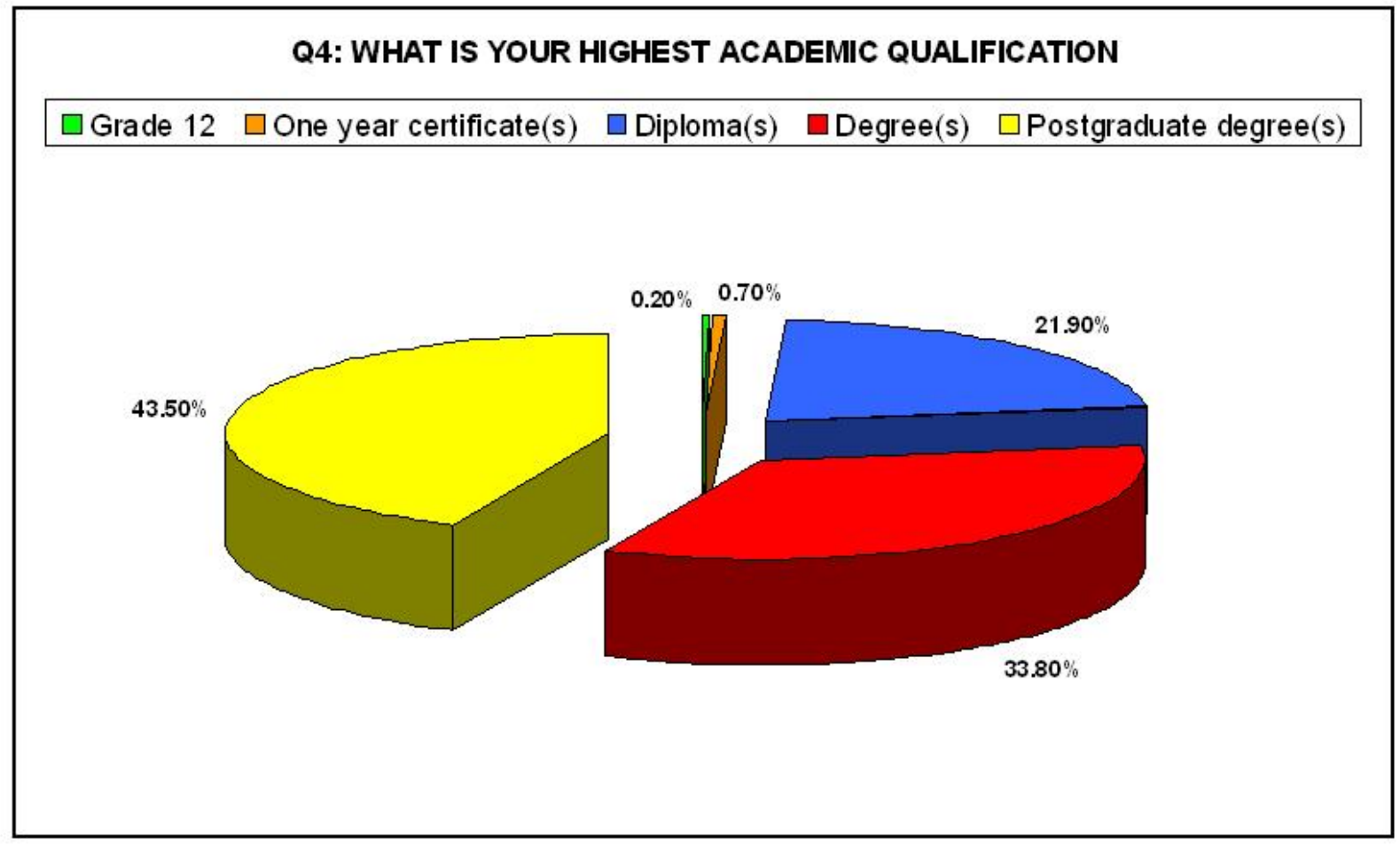

As can be seen in Figure 3, the majority of alumni (37,9\%) fell into the 36 to 49 years age group, with $29,4 \%$ that fell into the 22 to 25 years age group. The age group for 26 to 35 years made up 19,5\% of the sample, while 10,5\% of the respondents were between 50 and 59 years of age. Only 2,0\% of the respondents were older than 60 years. The low percentage for the 18 to 21 age group could be due to the fact that very few students have completed a tertiary qualification at that age, and would not yet be classified as alumni of an institution, but rather as active students.

When looking at the age spread of the alumni of the UJ it was anticipated that access and usage of ICTs would not be a stumbling block for alumni, as the number of alumni from the older generations were in the minority. The fear of using technology, dubbed 'Technophobia' (Gilbert et al. (author, please give the names of all the authors in this first citation) 2003:2) was more apparent in the older generation due to an apparent lack of skills, experience and confidence in using these technologies. The majority of the alumni of the UJ fell into the most active age groups (between 26 and 49 years old) in terms of ICT utilization.

Figure 3 Representation of the responses to Question 5 of the survey 


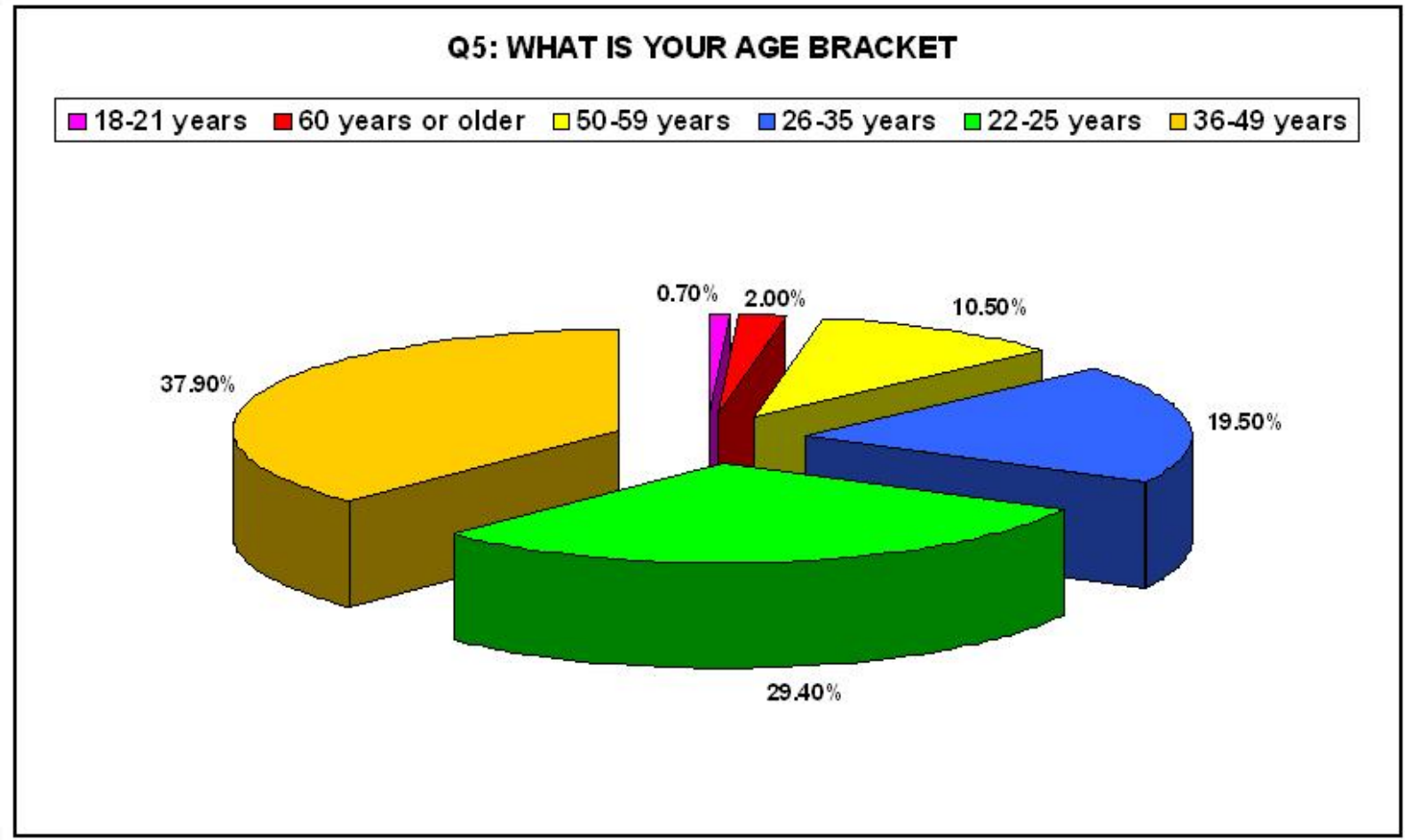

As a result of the stratified sampling, with gender as one of the determining factors, the representation of males and females in this study was nearly 50/50, with 49,7\% males and 50,3\% females (see Figure 4). Gender had been identified as a factor influencing the digital divide in South Africa. However, when looking at the summary of the hypotheses tests with regards to gender of alumni of the UJ and ICT usage patterns (according to the listed variables in column 1 of Table 2), it is evident that gender had either no effect or a small effect at the most on the use and access of ICTs of the alumni of UJ. In cases where the effect was small, males were dominant with the use and access to ICTs, with the exception of Internet access at work, where females were dominant.

Figure 4 Representation of the responses to Question 6 of the survey

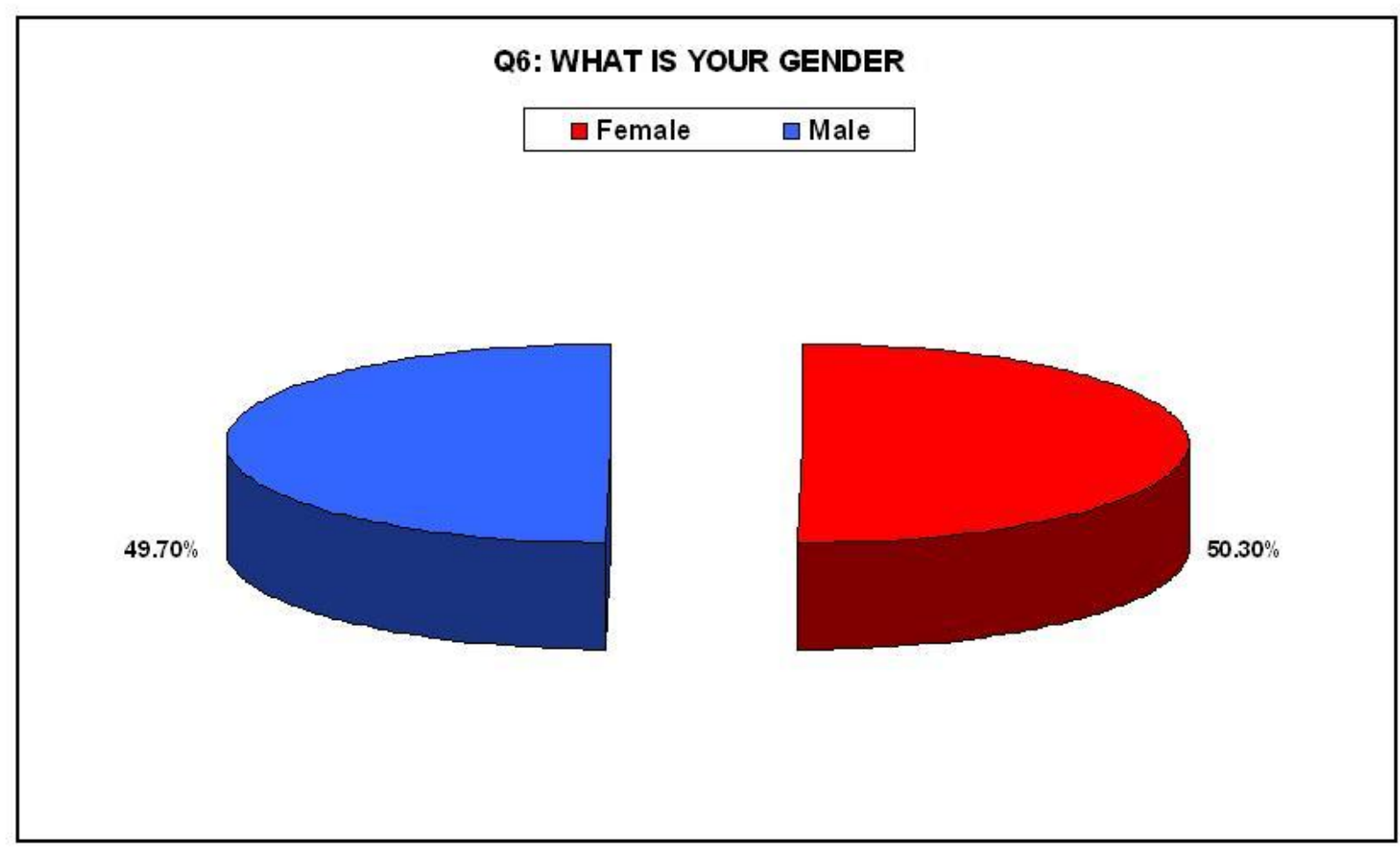

Table 2 Effect of gender on the ICT access and usage patterns of alumni of UJ

\begin{tabular}{|l|l|l|l|}
\hline Variables & $\begin{array}{l}\text { Chi-square test }(\boldsymbol{p} \text { - } \\
\text { value) }\end{array}$ & $\begin{array}{l}\text { Symmetric measures (effect } \\
\text { size) }\end{array}$ & $\begin{array}{l}\text { Interpreted } \\
\text { effect }\end{array}$ \\
\hline 1. Listen to the radio & 0,997 & 0,003 & None \\
\hline 2. Watch television & 0,780 & 0,029 & None \\
\hline 3. Have a telephone conversation (land line) & 0,791 & 0,028 & None \\
\hline & & &
\end{tabular}




\begin{tabular}{|l|l|l|l|}
\hline 4. Use a fax machine & 0,005 & 0,135 & Small \\
\hline 5. Have a cell phone conversation & 0,013 & 0,121 & Small \\
\hline 6. Send an SMS message & 0,090 & 0,091 & None \\
\hline 7. Receive an SMS message & 0,347 & 0,060 & None \\
\hline 8. Work on a computer & 0,006 & 0,133 & Small \\
\hline 9. Surf on the WWW & 0,026 & 0,112 & Small \\
\hline 10. Do Internet banking & 0,000 & 0,173 & Small \\
\hline 11. Send e-mail & 0,001 & 0,154 & Small \\
\hline 12. Receive e-mail & 0,002 & 0,145 & Small \\
\hline 13. Use instant messaging & 0,039 & 0,106 & Small \\
\hline 14. Have Internet access at home & 0,267 & 0,046 & None \\
\hline 15. Have Internet access at work & 0,005 & 0,116 & Small \\
\hline 16. Have cell phones supporting WAP & 0,377 & 0,058 & None \\
\hline 17. Have cell phones supporting Bluetooth & 0,583 & 0,043 & None \\
\hline 18. Using calendar facilities on cell phone & 0,554 & 0,026 & None \\
\hline $\begin{array}{l}\text { 19. Synchronizing cell phone calendar with PC } \\
\text { calendar }\end{array}$ & 0,018 & 0,102 & Small \\
\hline
\end{tabular}

Although South Africa has 11 official languages, this did not seem to pose a major problem for the Alumni Office of the UJ, as the majority of alumni were either English speaking (48,2\%) or Afrikaans speaking (33,3\%). The other two languages that were spoken the most by alumni were Sesotho (5.4\%) and isiZulu (5\%) (see Figure 5).

Figure 5 Representation of the responses to Question 7 of the survey

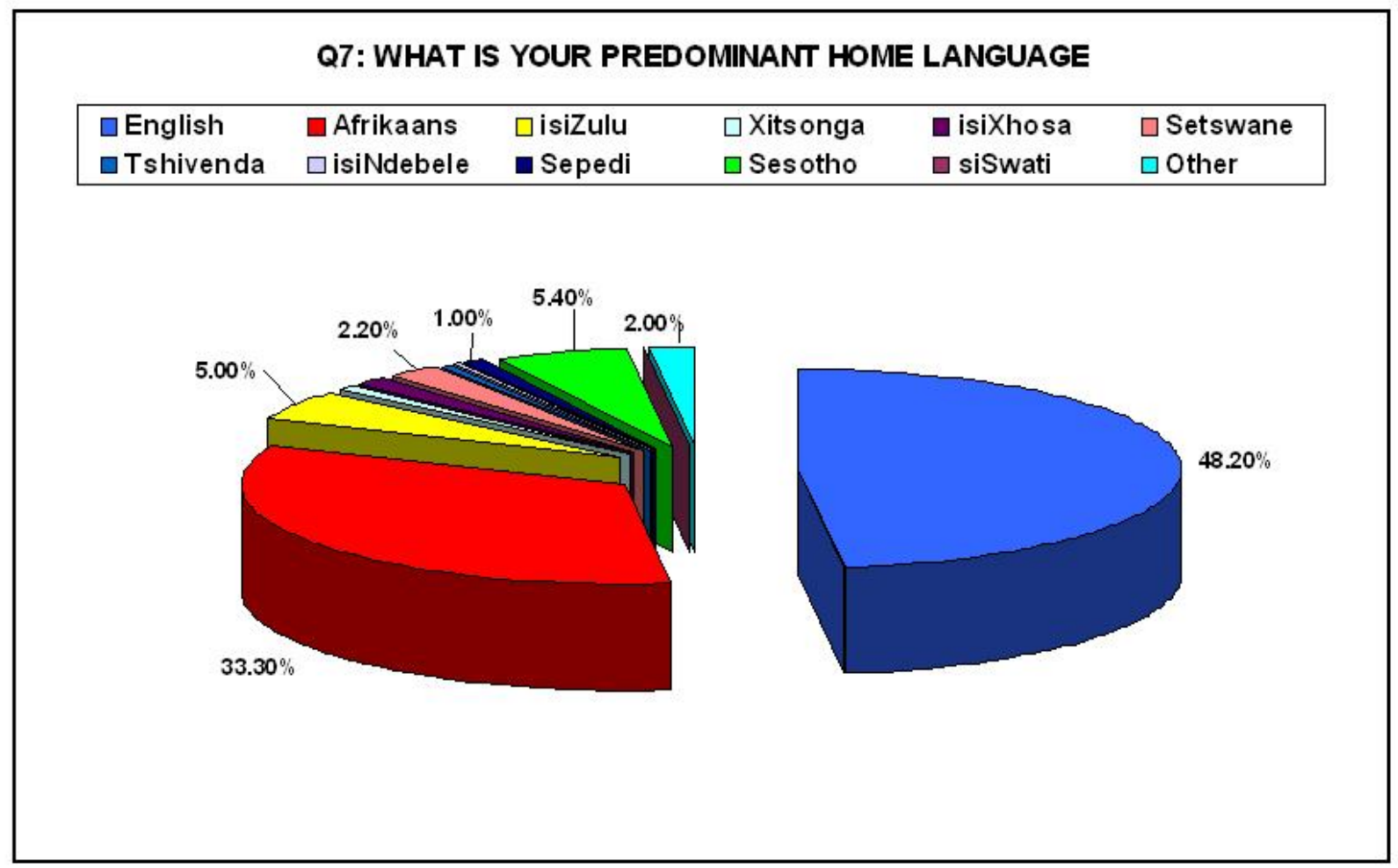

Figure 6 shows an overwhelming majority of 76,9\% in favour of English as the preferred language of communication at alumni's tertiary institution. When comparing this to the $23,1 \%$ of alumni preferring Afrikaans as communication language, it is clear that the traditional notion of RAU being an academic institution solely for Afrikaans-speaking individuals has changed dramatically since RAU's conception in the late 1960s. This could be due to the fact that English is a language recognized worldwide, with many English textbooks and courses being prescribed.

Language barriers were not anticipated to be a problem for alumni with regard to ICT (especially Web and Internet) usage and access, as it would be safe to assume that most (if not all) of the alumni of the UJ, including the Afrikaans-speaking individuals, had a firm grip on the English language. Even though there were differences in home language among the alumni, English was widely accepted to be the language of use at tertiary education level, which simplified the diverse language situation significantly. This made the possibilities for effective information dissemination much more viable than should this not have been the case.

Figure 6 Representation of the responses to Question 8 of the survey 


\section{Q8: PREFERRED COMMUNCATION LANGUAGE AT TERTIARY INSTITUTION}

\section{$\square$ English $\square$ Afrikaans}

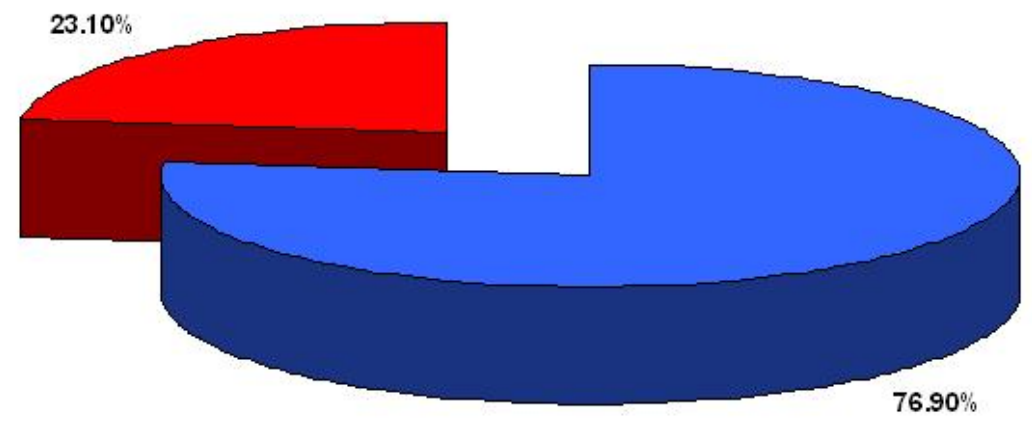

The percentages reflected in Figure 7 illustrate that the majority $(77,3 \%)$ of alumni were employed on a full-time basis, indicating average to above average socio-economic circumstances. Keeping the high South African unemployment rate in mind, this was a very privileged group of individuals in comparison to the rest of the South African population. Together with the part-time employed alumni $(4,2 \%)$, the contract-base employed alumni (3,5\%), the entrepreneurial self-employed alumni $(7,8 \%)$ and the retired alumni $(1,3 \%)$, the average income of this target audience should make access to and ownership of ICTs a general occurrence.

Figure 7 Representation of the responses to Question 10 of the survey

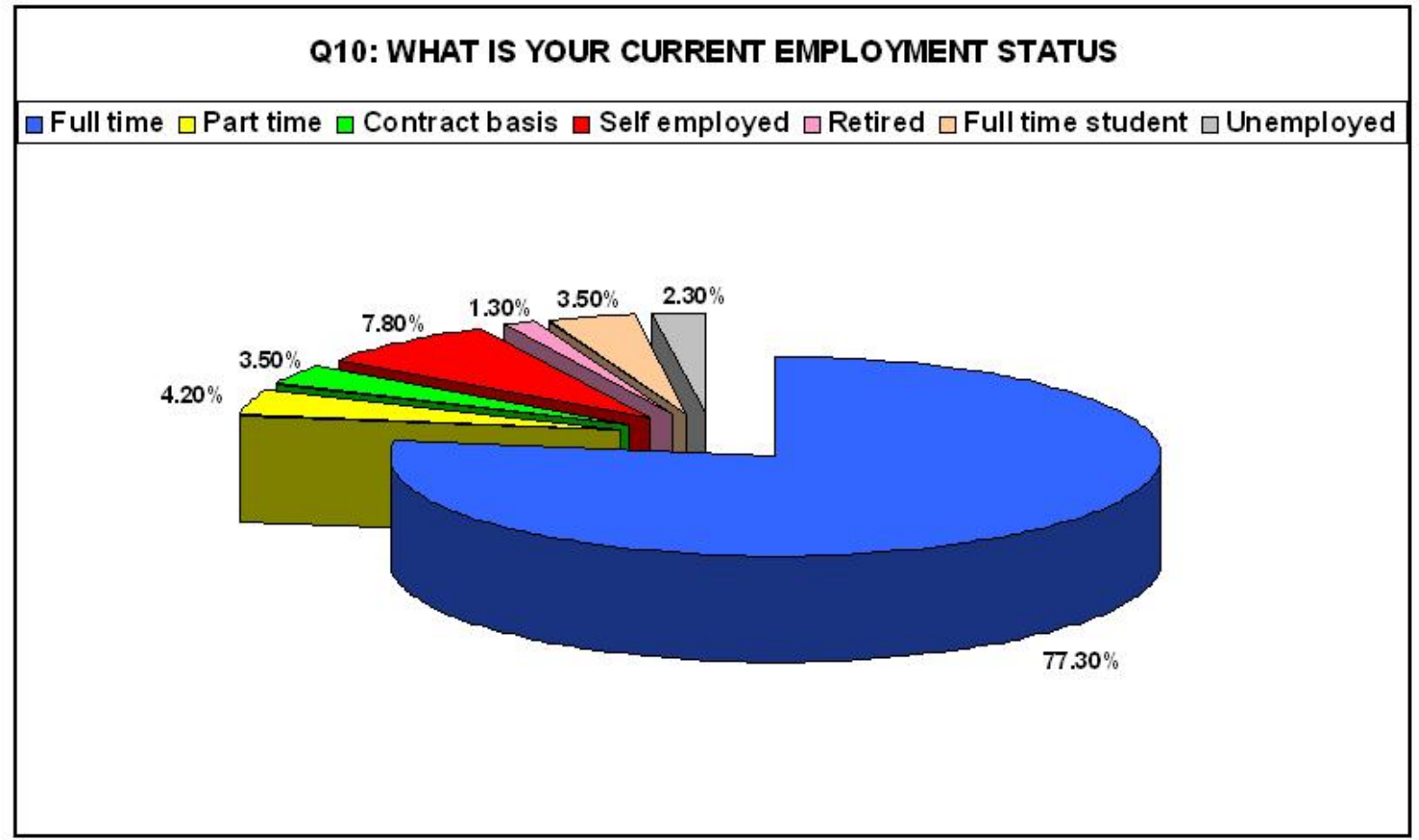

When comparing the socio-economic situations of alumni of the UJ with the variables listed in column 1 of Table 3 , the effect of this factor on the access and use of ICTs could be established. The different categories given in Chart 6 have been grouped together to make a differentiation between alumni describing themselves as Poor to Average, and those alumni who fall under the categories of Above Average and Affluent.

Table 3 Effect of socio-economic circumstances on ICT access and usage patterns of the alumni of the UJ

\begin{tabular}{|l|l|l|l|}
\hline Variables & $\begin{array}{l}\text { Chi-square } \\
\text { test } \\
(p \text {-value) }\end{array}$ & $\begin{array}{l}\text { Symmetric } \\
\text { measures } \\
\text { (effect size) }\end{array}$ & Interpreted effect \\
\hline & & &
\end{tabular}




\begin{tabular}{|c|c|c|c|}
\hline 1. Listen to the radio & 0,437 & 0,053 & None \\
\hline 2. Watch television & 0,032 & 0,108 & Small \\
\hline 3. Have a telephone conversation (land line) & 0,000 & 0,163 & Small \\
\hline 4. Use a fax machine & 0,928 & 0,016 & None \\
\hline 5. Have a cell phone conversation & 0,093 & 0,090 & None \\
\hline 6. Send a SMS message & 0,012 & 0,123 & Small \\
\hline 7. Receive a SMS message & 0,475 & 0,050 & None \\
\hline 8. Work on a computer & 0,032 & 0,108 & Small \\
\hline 9. Surf on the WWW & 0,001 & 0,161 & Small \\
\hline 10. Do Internet banking & 0,000 & 0,213 & $\begin{array}{l}\text { Small (leaning towards } \\
\text { Medium) }\end{array}$ \\
\hline 11. Send e-mail & 0,000 & 0,224 & $\begin{array}{l}\text { Small (leaning towards } \\
\text { Medium) }\end{array}$ \\
\hline 12. Receive e-mail & 0,000 & 0,215 & $\begin{array}{l}\text { Small (leaning towards } \\
\text { Medium) }\end{array}$ \\
\hline 13. Use instant messaging & 0,018 & 0,117 & Small \\
\hline 14. Have Internet access at home & 0,000 & 0,215 & $\begin{array}{l}\text { Small (leaning towards } \\
\text { Medium) }\end{array}$ \\
\hline 15. Have Internet access at work & 0,057 & 0,082 & None \\
\hline 16. Have cell phones supporting WAP & 0,478 & 0,050 & None \\
\hline 17. Have cell phones supporting Bluetooth & 0,916 & 0,017 & None \\
\hline 18. Using calendar facilities on cell phone & 0,338 & 0,040 & None \\
\hline $\begin{array}{l}\text { 19. Synchronizing cell phone calendar with PC } \\
\text { calendar }\end{array}$ & 0,644 & 0,021 & None \\
\hline
\end{tabular}

From Table 3 it is clear that the socio-economic circumstances of alumni mostly had a small effect on their access and usage patterns with regard to ICTs, although there were more significant effect sizes to be noted in the Internet activities of these groups. The Above Average and Affluent groups were considerably more active in doing Internet banking, sending or receiving electronic mails and surfing the Web on a daily basis (62\% Above Average respondents versus 45,6\% Poor to Average respondents) than their less affluent counterparts. In addition, this group had nearly 20\% more access to the Internet from home than the Poor to Average respondents. This could mainly be ascribed to the relatively high costs (compared to the Internet access cost in other countries) involved to privately connect and spend time on the World-Wide Web in South Africa.

\section{Section B: Information and communication media and technology}

The results of question 11, as depicted in Figure 8, relating to the frequency of use of specific ICTs, showed some interesting usage patterns among the respondents. A surprising majority (76,3\%) of the respondents never used Instant Messaging as a means to transmit information, preferring the use of electronic mail on a daily basis. From the total number of respondents, $68,6 \%$ used e-mail to send information on a daily basis, while $14,2 \%$ used it to send information at least every two to four days (i.e. a total of $82,8 \%$ ). Of the respondents, $71,3 \%$ used e-mail daily to receive information, while $14,2 \%$ used it at least every two to four days to receive information (i.e. a total of $85,5 \%$ ).

The most popular ICTs to be used on a daily basis by respondents were:

- Cellular telephone - conversational (94,5\%)

- Radio (92,7\%)

- Personal computer $(90,7 \%)$

- Land line telephone - conversational $(85,8 \%)$

- Television $(78,1 \%)$.

Sending (a total of $84,8 \%$ ) and receiving (a total of $89,6 \%$ ) SMS text messages and surfing the World-Wide Web (a total of 75,4\%) seem to be popular activities for these respondents as the majority of them engaged in it once a day or at least every two to four days. This again emphasies that alumni of the UJ did not have a problem with access and the use of ICTs due to the digital divide in South Africa. To assume that the minority respondents, who answered that they never used these technologies and services, had no access to these ICTs might be a wrong assumption, as it might be out of own choice not to use these technologies although availability might not be an issue.

Insert figure 8 here

Figure 8 Representation of the responses to Question 11 of the survey 


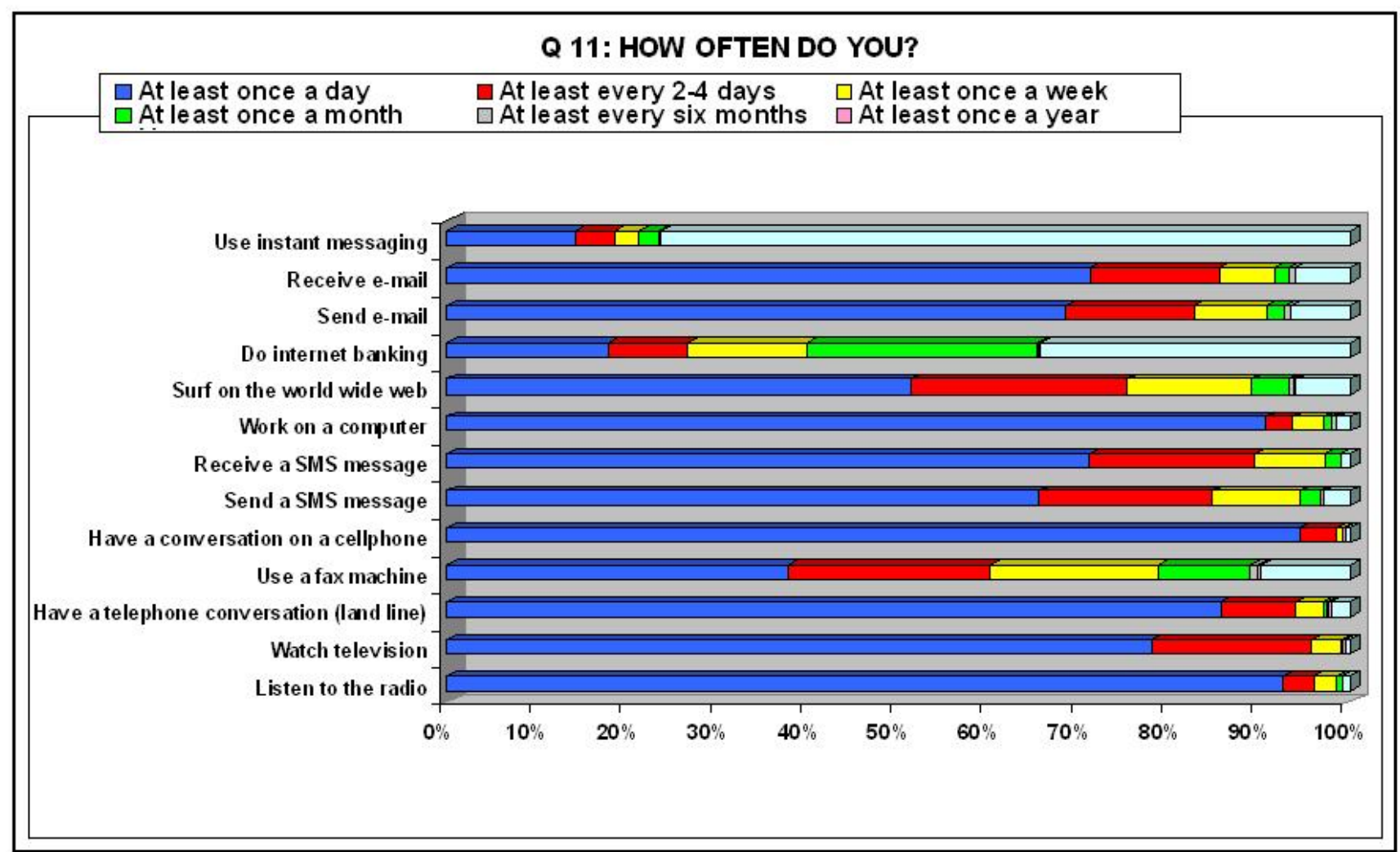

As seen in Figure 9, the majority of alumni (82,3\%) had Internet access at work, while 59,4\% had Internet access at home. The relatively high connection rate to the Internet in South Africa might be the reason why respondents preferred to access the Internet from work (where it is not billed to their own account) rather than from home. The 10,9\% of respondents who accessed the Internet from their tertiary institution might be due to the fact that only $17,6 \%$ of the respondents were currently registered for a qualification at either RAU or TWR (see Figure 9). The RAU Alumni Association also offered its members the opportunity of gaining access to the Internet through its benefits programme. Only 4,2\% of the respondents made use of other access points, such as Internet cafes, to go online.

Figure 9 Representation of the responses to Question 12 of the survey

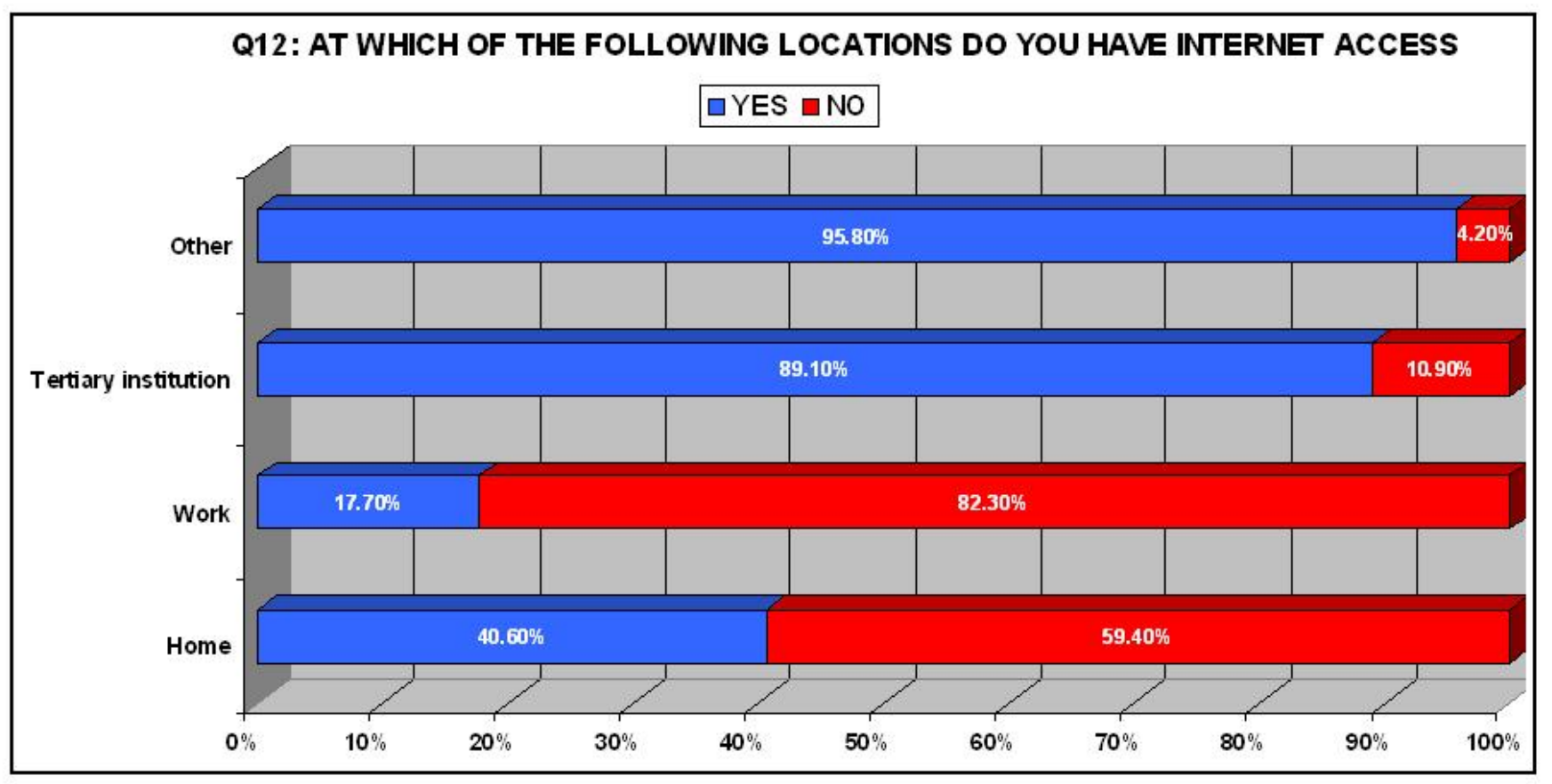

Figure 10 Representation of the responses to Question 3 of the survey 


\section{Q3: ARE YOU CURRENTLY REGISTERED FOR A QUALIFICATION}

\section{TWR $\square$ RAU $\square$ None}

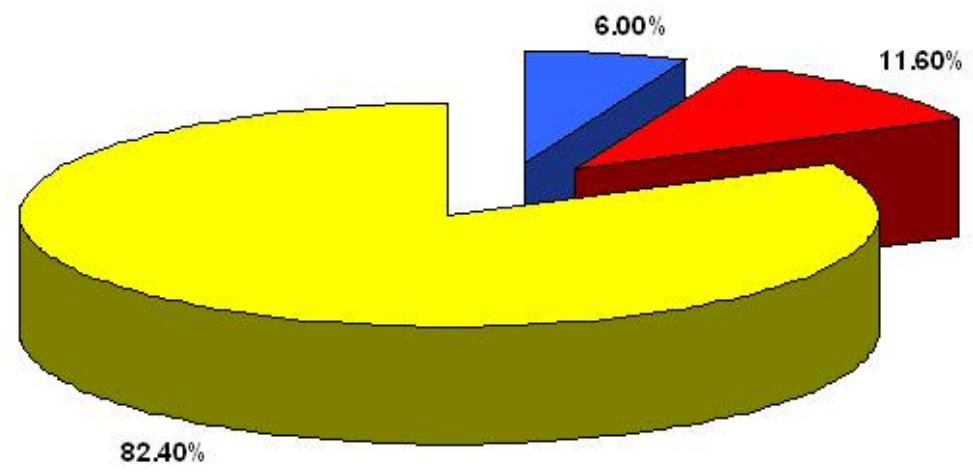

Of all the ICTs available, the cellular telephone is probably the one with the most potential for interactive and relatively cheap information dissemination. As $99 \%$ of respondents had a cellular telephone, accessibility was definitely not an issue. The small and portable nature of the device makes the recipient of the information reachable at all times on a personalized level. Figure 11 illustrates that although $99 \%$ of the respondents had a cellular telephone, not all used their devices optimally. While $60,6 \%$ of the respondents at least used a calendar facility on their cell phones, $83,8 \%$ of them did not synchronize their cell phone calendars with their personal computer calendars. Nearly half the respondents also seemed to own relatively outdated cellular phones, as 53,5\% of them owned devices that did not support Bluetooth. Of the total number of respondents, $16,60 \%$ said that they were not sure whether their cell phones supported Bluetooth, while $29,9 \%$ were sure that their devices supported Bluetooth.

However, this does not mean that they actually used this functionality on their devices. The majority of respondents (53,6\%) were sure that their cellular devices supported WAP (again this does not imply actual usage), while 33,1\% said theirs did not, and 10,4\% were not sure. When looking at the results of question 11 , with $94,5 \%$ of the respondents having telephone conversations on their cellular devices on a daily basis, this, along with sending and receiving SMS text messages, seems to be the most important use that they had (at that time) for this ICT. This again emphasizes that the mere development of technology does not necessarily guarantee the instant usage of the benefits it might offer.

Figure 11 Representation of the responses to Question 14 of the survey

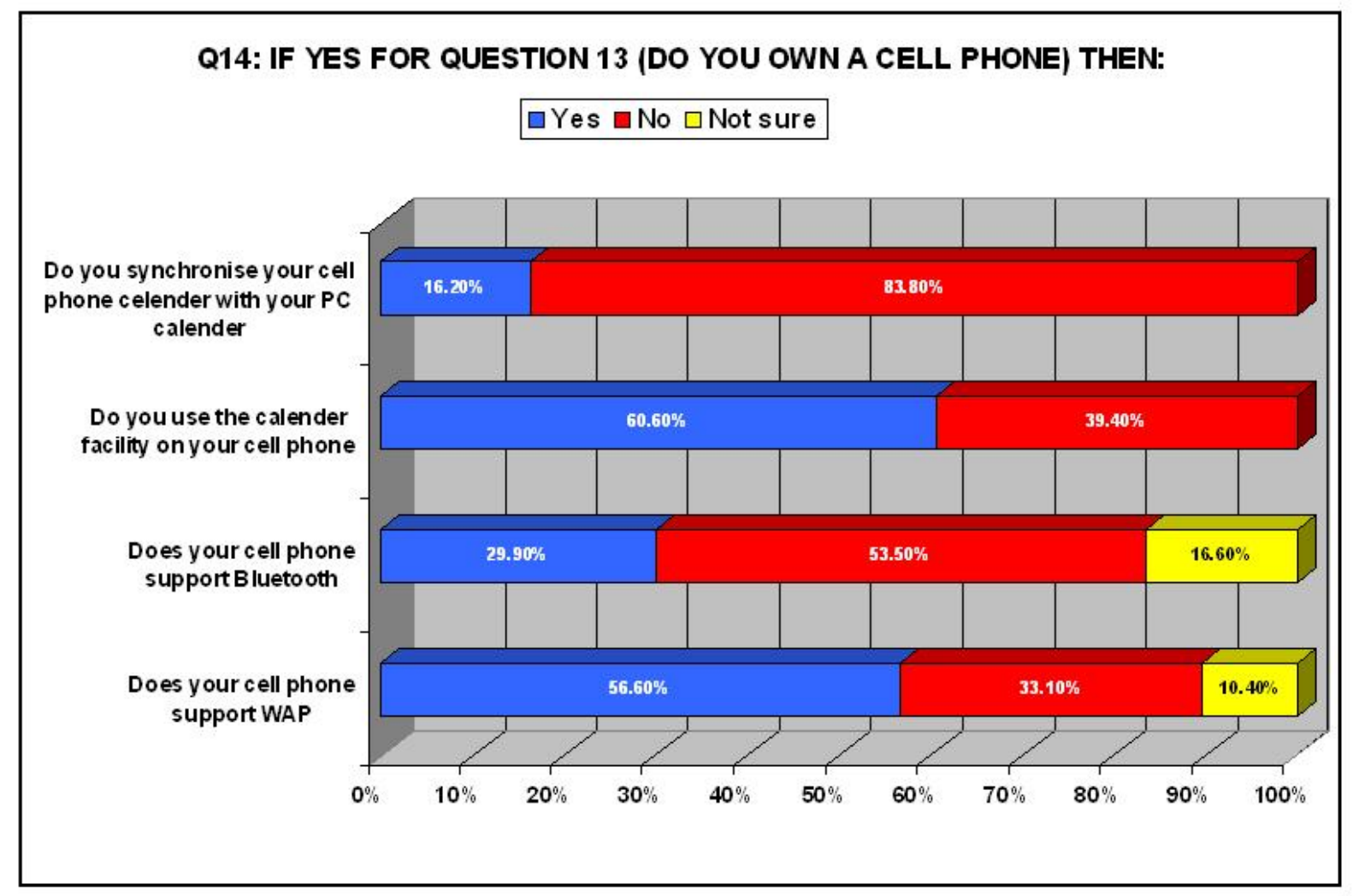


As portrayed in Figure 12, the vast majority (86,7\%) of respondents preferred to receive the information from their institution where they had graduated, by means of electronic mail or by means of the World-Wide Web (i.e. Web sites). Although lacking far behind the percentage favouring e-mail and Web communication, traditional mail featured $(51,1 \%)$ as the second most preferred medium for the respondents to receive information from their institution.

Receiving information through media such as electronic billboards, television, telephone, radio and fax machine was the least preferred method. This could be due to the fact that respondents might have been more selective with regard to the information they exposed themselves to, as these mentioned media are quite intrusive and mostly impersonal by nature. It is also interesting to see that, while the most popular ICTs for respondents on a daily basis were the television, radio and telephone, these were the less preferred methods for alumni to receive information from their institution. An assumption could be made that the type of information that alumni wanted to receive from their institution was not suitable for transfer via the indicated least-preferred media.

An interesting finding is that only $37,7 \%$ of the respondents wanted to receive institutional information by means of the printed media (such as newspaper advertisements). This was quite unexpected as the majority of the overall marketing campaigns and efforts of RAU and TWR had always focused mainly on using the printed media to communicate the brand message to its target audiences.

Figure 12 Representation of the responses to Question 16 of the survey

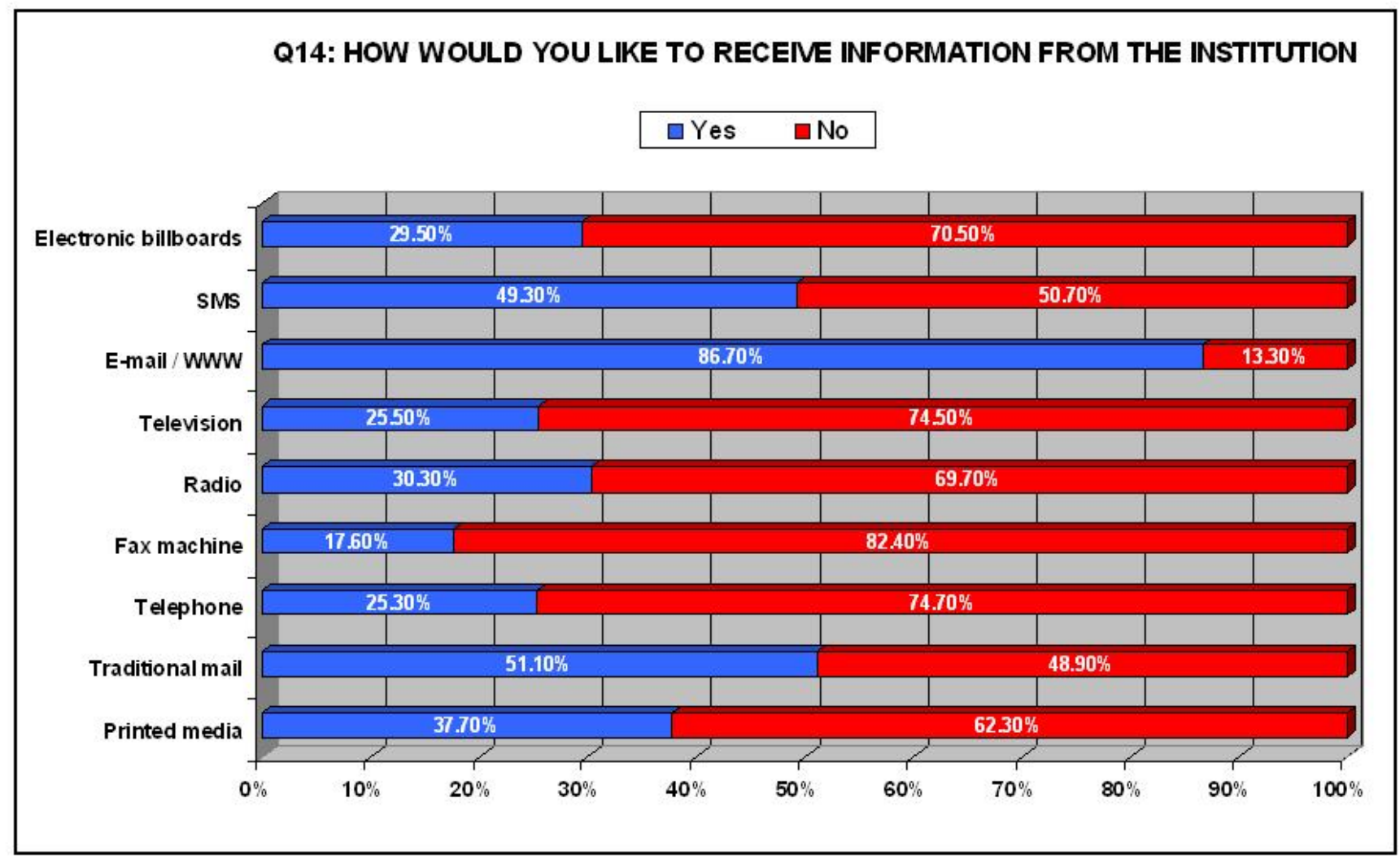

\section{Conclusion}

The empirical research uncovered significant findings that would assist the Alumni Office of the UJ in adopting an appropriate approach to establishing and maintaining valuable relations with its existing and future alumni through the use of ICTs. As reflected in the research findings, the alumni target audience of the UJ forms part of a privileged section of the South African population. Their socio-economic circumstances, levels of education, language capabilities and ICT access and utilization patterns put them in a favourable position with regard to bridging the global digital divide. This affords the Alumni Office of the UJ a golden opportunity fully to exploit the interactive information sharing and networking options available via these technologies.

The final conclusion that could be made from this research project is that ICTs can enable the Alumni Office of the UJ to a great extent to disseminate information effectively to its alumni.

\section{References}

Cohen, J. 1998. Statistical power analysis for the behavioural sciences. 2nd edition. Hillsdale, NJ: Erlbaum.

Cullen, R. Addressing the digital divide. 2001. Online Information Review, 25(5):311-325.

Fitzgerald, S. 2003. Generation now. Classic currents (2000-2003). Council for Advancement and Support of Education.

Gilbert, D., Lee-Kelley, L. and Barton, M. 2003. Technophobia, gender influences and consumer decision-making for technology-related products. European Journal of Innovation Management, 6(4):253-263. 
Gorman, B. 1989. Higher education consulting services. KPMG Peat Marwick. New York.

Rosenthal, R., Rosnow, R.L. and Rubin, D.B. 2000. Contrasts and effect sizes in behavioural research: a correlational approach. Cambridge: Cambridge University Press.

Rowley, J. 2004. Researching people and organisations. Library Management, 25(4/5):208-214.

Stokes, D.E. 1997. Pasteur's quadrant: basic science and technological innovation. Brookings Institution Press.

Stone, W.E. 2001. Rethinking our craft. Currents Magazine (CASE). [Online]. Available WWW: http://www.case.org. (Accessed 17 January 2006).

\section{Disclaimer}

Articles published in SAJIM are the opinions of the authors and do not necessarily reflect the opinion of the Editor, Board, Publisher, Webmaster or the Rand Afrikaans University. The user hereby waives any claim he/she/they may have or acquire against the publisher, its suppliers, licensees and sub licensees and indemnifies all said persons from any claims, lawsuits, proceedings, costs, special, incidental, consequential or indirect damages, including damages for loss of profits, loss of business or downtime arising out of or relating to the user's use of the Website.

ISSN 1560-683X

Published by InterWord Communications for Department of Information and Knowledge Management,

University of Johannesburg 